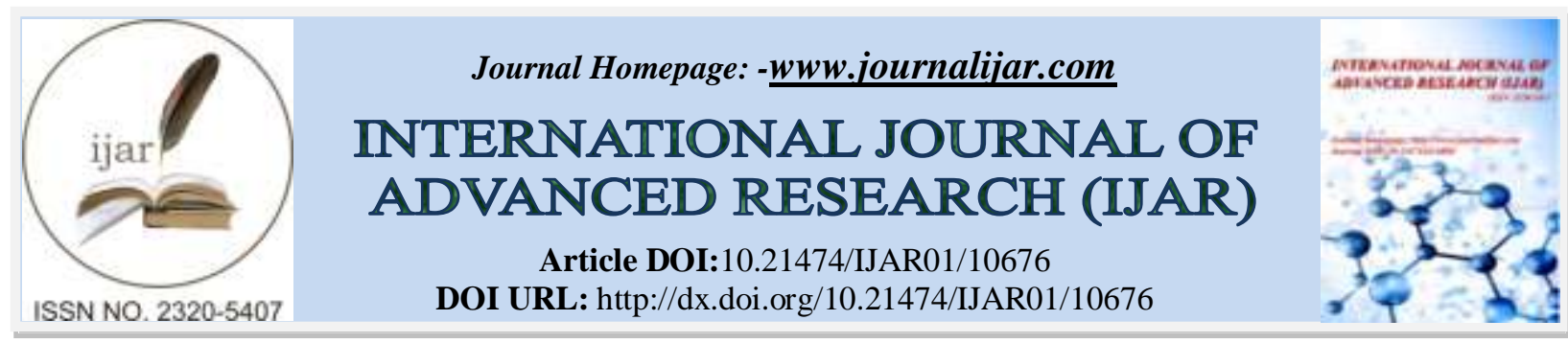

RESEARCH ARTICLE

\title{
EFFICACY OF NEW ROOT CANAL IRRIGANT ACTIVATION SYSTEMS ON REMOVAL OF SMEAR LAYER
}

\section{Nehal F. Sharaf ${ }^{1}$ and Rasha F. Sharaf ${ }^{2}$}

1. Researcher of Endodontics, Restorative \& Dental Materials Department, National Research Centre. Cairo, Egypt.Orcid Number 0000-0001-6505-2854.

2. Researcher of Pediatric Dentistry, Orthodontics \& Pediatric Dentistry Department, National Research Centre. Cairo, Egypt.Orcid Number 0000-0001-8762-602X.

\section{Manuscript Info}

Manuscript History

Received: 15 January 2020

Final Accepted: 17 February 2020

Published: March 2020

Key words:-

Smear layer, XP endo Finisher, EDDY

\section{Abstract}

The purpose of this study was to examine the effectiveness of recent irrigant activation methods on cleanliness of the root canals and removal of the smear layer.

Materials and Methods:Thirty single-rooted human mandibular premolars with single straight canals were used in this study. Root canals were mechanically prepared using Path files then BT race system till size (\#35/0.04). Teeth were randomly divided into 3 groups, according to the irrigatnt activation method used. Control group (conventional irrigation) and two experimental groups according to the method used for irrigant activation in the root canal, EDDY group and XP endo finisher group $(n=10)$. Then teeth were split vertically to be prepared for SEM examination. The root canals were photomicrographed at magnification of $6000 \mathrm{X}$ to assess the presence of smear layer in coronal, middle, and apical thirds. Results showed significant increase of remaining smear layer at the apical third in all groups in comparison to middle and coronal thirds. Eddy and Xp endo finisher succeeded in removal of smear layer specially at the middle and apical third with significant difference than the conventional method without activation. There was non significant difference between Eddy and XP endo finisher in removal of smear layer at the middle and apical thirds.

Conclusion: New irrigant activation systems improves the removal of smear layer than the traditional syringe method.

Copy Right, IJAR, 2020,. All rights reserved.

\section{Introduction:-}

During root canal procedures, cleaning and shaping of the root canals is considered one of the most important procedures which greatly affects the outcome of the endodontic treatment. Smear layer is formed on the walls of the root canals during cleaning and shaping, this amorphous irregular layer is formed of organic pulpal remnants and inorganic dentinal debris accumulate which adhere onto the radicular canal wall. ${ }^{(1)}$ It has been reported that the smear layer seal the dentinal tubules and hinder the penetration of intracanalirrigants, disinfectants and sealers into the dentinal tubules, ${ }^{(2)}$ which may lead to compromising the seal of canal filling and increase the microleakage, it was also found that presence of this infected layer loaded with bacteria in the dentinal tubules, decrease the success 
rate of the root canal treatment. Smear layer is formed either when hand or rotary instruments are used in canal preparation. ${ }^{(3,4)}$

Different researches recommended removing the smear layer for better sealing of theobturation material to the canal wall. $^{(5)}$ Different irrigating solutions and devices have been used for better removal of the smear layer, the most commonly used irrigating solution in endodontics is sodium hypochlorite $(\mathrm{NaOCl})$, the common protocol for removal of smear layer includes the use of sodium hypochlorite $(\mathrm{NaOCl})$ followed by ethylenediaminetetraacetic acid (EDTA) because EDTA is a calcium-chelating agent, which is highly efficient in removal of the smear layer. ${ }^{(6)}$

XP-Endo finisher, is a new NiTi rotary file, it is semi-circular in shape with a $3 \mathrm{~mm}$ diameter. It was claimed that it has the ability to fit into the complex morphology of the rootcanals to clean it and remove the smear layer from the curved narrow canals. Being formed of NiTimake it able to change its shape and fit into any complex canal morphology andclean the irregularities and fins ${ }^{(7)}$

At low temperature $\left(20^{\circ}\right)$, the XP- file is in martensite phase so it is straight. When entered into the root canal at body temperature $\left(37^{\circ}\right)$, it changes to austenite phase considering its molecular memory. On cooling, it transforms back to the martensite phase and it returns to its straight form. ${ }^{(8,9)}$

Recently, EDDY (VDW, Germany), a new sonic powered system for activation of the irrigation was introduced, it is formed of flexible polyamide, which can be used with different root canals with complex morphology to perform adequate cleaning. ${ }^{(10)}$

EDDY is a disposable, sterile, noncutting tip where air scaler is used for its activation with 5000 to $6000 \mathrm{~Hz}$. So the aim of the current study was to examin the effectiveness of these recent irrigant activation methods on cleanliness of the root canals and removal of the smear layer. ${ }^{(11)}$

\section{Materials and Methods:- \\ Teeth selection:}

Thirty single-rooted human mandibular premolars with single straight canals and fully formed roots, extracted for periodontal reasons were collected and used in this study. Inclusion criteria were permanent teeth, intact apices, no previous root canal treatment, curvatures less than $30^{\circ}$, according to Schneider's classification. Exclusion criteria were root caries, cracks, and fracture lines. Mesiodistal and buccolingual radiographs were taken to confirm a single straight canal and canal space, excluding calcified root canals. The root lengths were standardized to $15 \mathrm{~mm}$ by decoronation, using a high-speed, water-cooled diamond disc. The tooth length was obtained by introducing \#10 Kfile (DentsplyMaillefer, Ballaigues, Switzerland) into the canal to the point of displaying its tip at the apical foramen. The working length was obtained by subtracting $1 \mathrm{~mm}$ from the tooth length. To simulate clinical conditions, the apical region of each root was sealed with a layer of OpalDam Green gingival barrier (Ultradent Products Inc,USA), avoiding extrusion of the irrigating solutions.

\section{Chemomechanical preparation of the root canals:}

Glide path was done using PathFiles (PF) (DentsplyMaillefer, USA). PF \#1 'purple' (13/0.02) then PF \#2 'white' (16/0.02) and PF \#3 'yellow' (19/0.02) were used at WL by using an endodontic engine 'X-Smart Plus' (DentsplyMaillefer, USA) at the suggested setting ' $300 \mathrm{rpm} \& 5 \mathrm{Ncm}$.

Mechanical preparation was done using, BT1 (\#10/0.06),BT2 (\#35/0.00) and BT3 (\#35/0.04).

Specimens were randomly divided into 3 groups, control group (conventional irrigation) and two experimental groups according to the method used for irrigant activation in the root canal, EDDY group and XP endo finisher group $(\mathrm{n}=10)$. Root canal instrumentation was performed by the same operator. In between files, canals were irrigated with $2 \mathrm{~mL}$ of $2.6 \% \mathrm{NaOCl}$ using a 5-mL syringe and 30-gauge double-side port NaviTip (Ultradent Products Inc, South Jordan, USA) calibrated to stop $-2 \mathrm{~mm}$ from the WL. After finishing chemomechanical preparation, 17\% EDTA (Ultradent Products Inc, South Jordan, USA) was agitated inside the canals as follows:

Group $1(n=10)$ Final rinse with 17\% EDTA and no agitation was performed. Group $2(n=10)$ Final rinse with 17\% EDTA and agitation using XP endo Finisher file at $800 \mathrm{rpm}$ for 60 seconds. Group 3 (n=10) Final rinse with 17\% EDTA agitation was performed using EDDY of size 25/.04. which was activated with 5000 to $6000 \mathrm{~Hz}$, using air scaler hand piece. 


\section{Preparation for scanning electron microscopic examination:}

Scanning electron microscopy (SEM) was used to evaluate the efficacy of removal of the smear layer of final irrigants. On the buccal and lingual surfaces of the root, longitudinal grooves were made using a diamond disc and were divided into two halves. One randomly chosen half of each specimen was coded and subjected to increasing concentrations of ethanol $(25 \%, 50 \%, 75 \%$, and $100 \%)$, mounted on aluminum holder, sputter coated with gold and then examined with SEM (JEOL-JSM- 6610LV, Tokyo, Japan) at $20 \mathrm{kV}$. The root canals were photomicrographed at magnification of 6,000X to assess the presence of a smear layer in coronal, middle, and apical thirds. Two blinded and previously calibrated observers scored the images employing the following criteria, $1=$ no smear layer, all dentinal tubules open; $2=$ small amount of smear layer, some dentinal tubules open; $3=$ homogeneous smear layer covering the root canal wall, only few dentinal tubules open; $4=$ complete root canal wall covered by a homogeneous smear layer, no open dentinal tubules; and $5=$ heavy, inhomogeneous smear layer covering the complete root canal wall.

Then data were collected and statistically analysed.

\section{Statistical analysis:}

Kruskal Wallis test was used to compare between different tested groups and different root sections followed by Mann-Whitney U test for multiple comparison with Dunn Bonferroni correction $(\alpha=0.05)$ (IBM SPSS, Version 23, Armonk, NY, USA).

\section{Results:-}

For the coronal section, results showed insignificant difference between tested groups ( $\mathrm{p}=0.727$ ), for the Middle and Apical section, Eddy group and XP showed a significant lower smear layer score compared to Control group ( $\mathrm{p}=0.005$ and $<0.001$, respectively).

For control group, coronal section showed a significant lower smear layer scores compared to middle and apical sections. For Eddy group, results showed insignificant different between coronal and middle sections. Apical section showed significant higher smear layer scores compared to both coronal and middle. For XP group, coronal section showed a significantly lower smear layer scores compared to the apical section.

Table (1):- Smear layer scoring of different tested groups.

\begin{tabular}{|c|c|c|c|c|c|c|c|c|c|c|c|c|c|c|c|c|}
\hline & \multicolumn{5}{|c|}{ Control } & \multicolumn{5}{|c|}{ EDDY } & \multicolumn{5}{|c|}{ XP-endo finisher } & \multirow[t]{2}{*}{ p-value } \\
\hline Scores & 1 & 2 & 3 & 4 & 5 & 1 & 2 & 3 & 4 & 5 & 1 & 2 & 3 & 4 & 5 & \\
\hline Coronal & 8 & 2 & 0 & 0 & $0^{\mathrm{a}}$ & 9 & 1 & 0 & 0 & $0^{\mathrm{a}}$ & 9 & 1 & 0 & 0 & $0^{\mathrm{a}}$ & $0.727 \mathrm{NS}$ \\
\hline Middle & 2 & 4 & 4 & 0 & $0^{\mathrm{Ab}}$ & 7 & 3 & 0 & 0 & $0^{\mathrm{Ba}}$ & 8 & 2 & 0 & 0 & $0^{\mathrm{Bab}}$ & $0.005 *$ \\
\hline Apical & 0 & 0 & 3 & 7 & $0^{\mathrm{Ab}}$ & 1 & 5 & 4 & 0 & $0^{\mathrm{Bb}}$ & 4 & 5 & 1 & 0 & $0^{\mathrm{Bb}}$ & $<0.001 *$ \\
\hline p-value & \multicolumn{5}{|c|}{$<0.001 *$} & \multicolumn{5}{|c|}{$<0.001 *$} & \multicolumn{5}{|c|}{$0.034 *$} & \\
\hline
\end{tabular}

Different uppercase letter within each row indicates significant different.

Different lowercase letter within each column indicates significant different.

*=significant, NS=Non-significant

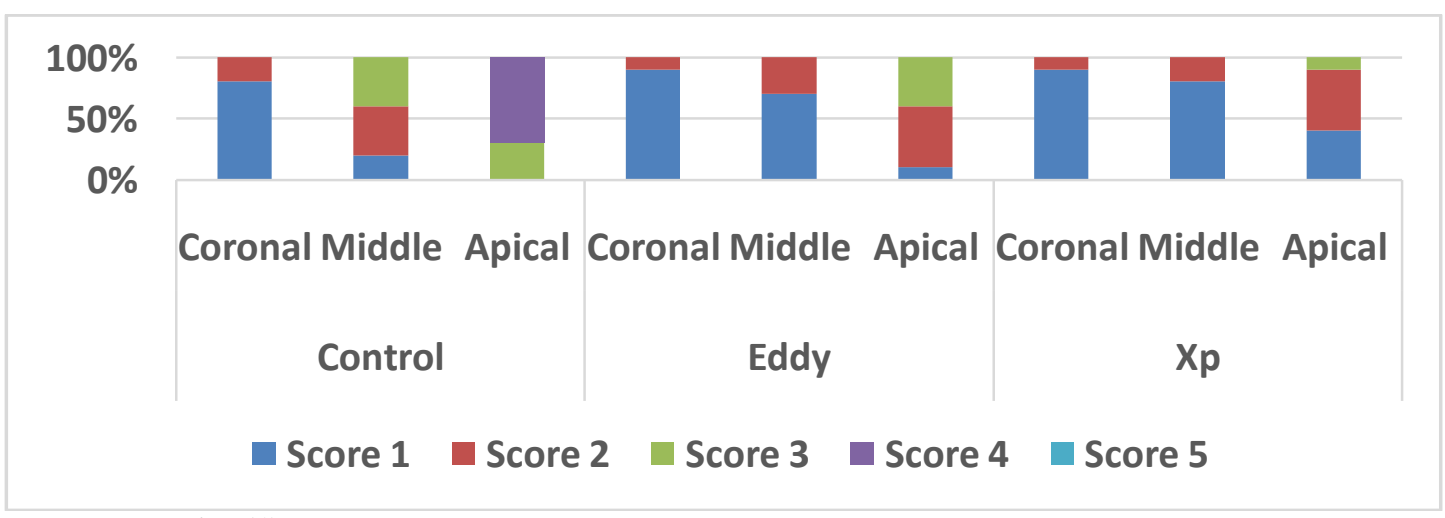

Fig. (1):- Bar chart showing the smear layer score percentage of tested groups. 

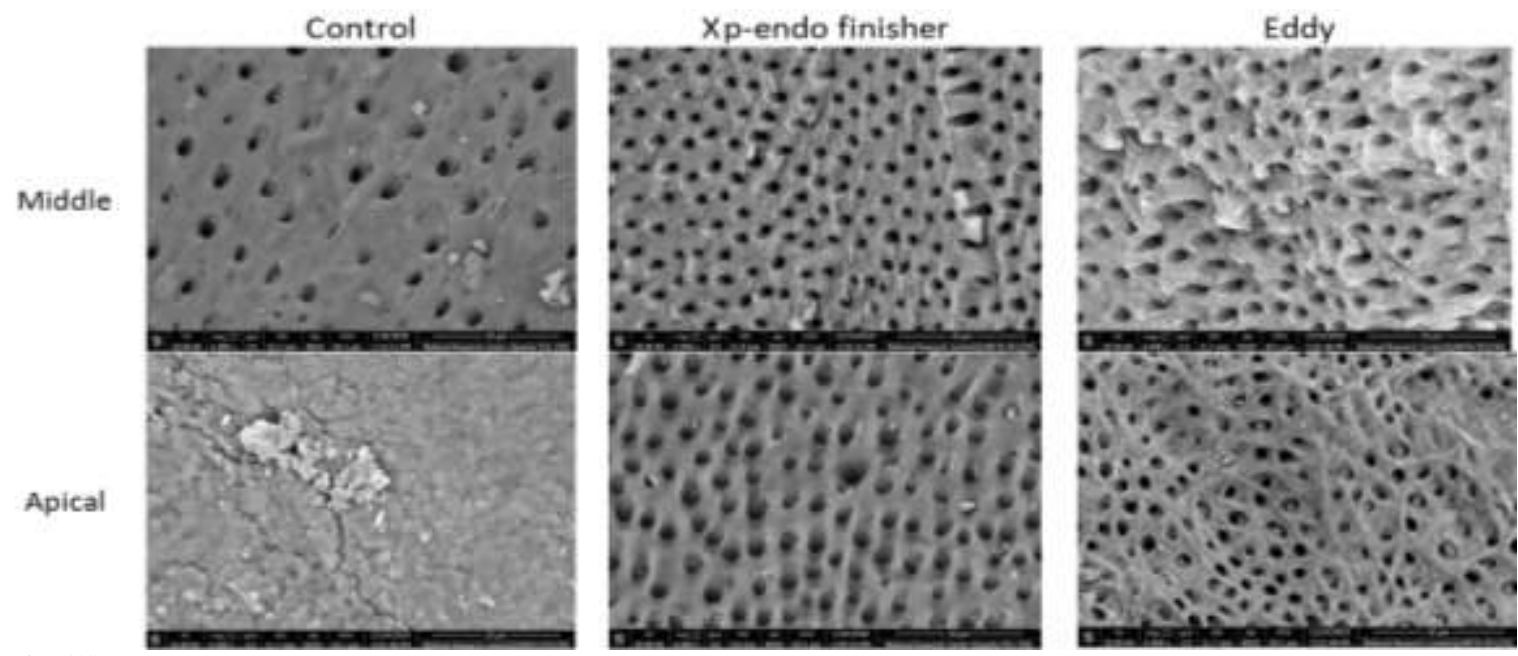

Fig.(2):- Photomicrographs (x6000) of remaining smear layer of the 3 tested groups( Control, XP endo finisher and EDDY) at the middle and apical thirds of the root canal.

\section{Discussion:-}

Success of root canal treatment depends on proper disinfection of the root canal and removal of microbes and infected tissues out of the canal. The goal of root canal treatment is to remove inflamed and infected pulp tissue from the root canals. This is performed by chemomechanicalpreparation, using endodontic files and irrigating solutions, where endodontic files help shaping of the canals and removal of the main bulk of infected pulp tissue remnants. ${ }^{(12)}$

The most commonly used irrigating solution is $\mathrm{NaOCl}$ because of its antibacterial action and ability to dissolve pulp tissue remnants, in addition to removal of the organic part of the smear layer. ${ }^{(13)}$

During root canal preparation, smear layer is formed on the root canal wall. It is formed of a superficial layer \& a deeper part embedded inside the dentinal tubules. This layer harbors bacteria and infected pulp tissue. It interferes with the performance of irrigating solution, preventing direct contact between the irrigant and microorganisms inside the canals and dentinal tubules. Some researches recommend the removal of smear layer before obturation to improve the bonding between the sealer and the root canal wall. ${ }^{(14)}$

Different irrigating solutions are used to remove this layer as EDTA, citric acid, MTAD and Q-mix. These irrigants are acid based, so they are used to remove the inorganic part of smear layer. ${ }^{(15)}$

Root canal system has complex anatomy, as it is formed of fens, isthmus and lateral canals. These areas can never be reached and cleaned by the endodontic files, so the root canal surface at these areas of the root canal system retains pulp tissue remnants and microorganisms which are difficult to be reached and cleaned even with the most innovative instruments for canal preparation. These infected areas may affect the prognosis and success rate of the root canal treatment. The only material which can reach these areas is the irrigating solution, so irrigating solutions have a great role in chemical cleaning and disinfection of these inaccessible areas, and help dissolving the pulp tissue remnants and microorganisms hidden there, improving the prognosis of root canal treatment. ${ }^{(16)}$

Syringe irrigation is used to deliver the irrigating solution to the root canal, but this doesn't insure reaching of the irrigating solution to all parts of the canal, specially the apical third, where apical vapour lock is formed. The apical vapour lock is an air bubble entrapped at the end of micro channels (root canals) at the distal end of irrigant delivery, preventing direct contact between this irrigant and walls of the apical part of the root canal, preventing the irrigating solution from performing its action at this part of the canal. ${ }^{(17)}$ Size of canal preparation is another factor which affects the extension and action of irrigating solution, so in this study root canals were prepared to size \#35/0.04. This size insure deeper penetration of the irrigation needle reaching the apical part of the canal, ${ }^{(18,19)}$ while the taper of the canal affects the flow \& amount of irrigating solution, improving root canal debridement. ${ }^{(20)}$ Irrigating solutions need an activation method to help reaching inaccessible areas of the root canals as isthmus, fins and to 
break the apical vapour lock. Irrigant activation helps direct contact of the irrigant with different parts of the canal and improve the irrigant performance. ${ }^{(21)}$

In the current study, both Xp endo finisher and Eddy groups created cleaner surface and less smear layer at the middle and apical thirds of the root canal walls, in comparison to the control group where no irrigant activation methods were used. ${ }^{(22,23)}$

Xp endo finisher depends on shape memory of the Niti alloy, as it has a sickle curved shape when entered into the root canal at body temperature $\left(37^{\circ}\right)$ (austenitic phase) which allows it to contact the root canal walls and pushing the irrigant to the inaccessible areas and apical third of the canal. This unique shape with the non cutting flutes help scrubbing of the smear layer on the dentin walls without causing any changes to the dentin shape, so help cleaning of the canal walls and removal of smear layer. When XP endo finisher cools down $\left(20^{\circ}\right)$ it becomes straight (martensitic phase). ${ }^{(22,24)}$

Eddy is a sonic activated polyamide tips, which causes 3 dimensional movement of the irrigating solution by acoustic streaming and cavitation. It helps penetration of the irrigant to the inaccessible areas and apical third of the canal to clean it and help removal of the smear layer. ${ }^{(11,25)}$

In this study both Xp endo finisher and Eddy improved the action of irrigating solutions on removal of smear layer specially at the middle and apical thirds of the canal in comparison to the traditional syringe irrigation without activation, where the irrigant couldn't completely remove smear layer specially at the apical third of the canals. ${ }^{(11,22,}$ 25)

Regardless the use of irrigant activation method or not, it is evident that the amount of smear layer remaining at the coronal third was less than that at the middle and apical thirds in all groups. It was found that the amount of smear layer remaining after mechanical preparation increases as we go more apical in all groups, this could be due to the decrease in root canal diameter at the apical third than the coronal third and less flow of the irrigating solution at the apical part than the coronal, so the root canal wall was subjected to less amount of irrigating solution. ${ }^{(19,26)}$ The formation of apical lock also may interfere with the flow of irrigant to the end of the canal. In this study, Xp endo finisher and Eddy showed less remaining smear layer at the apical part because of their action in disruption of the apical vapour lock, also continuous rotation of XP-endo finisher and acoustic streaming created by Eddy caused more flow of the irrigating solution scrubbing the smear layer and removing it. ${ }^{(1,24,25)}$

Under the conditions of the current study, it can be concluded that using an activation method as XP endo finisher or Eddy with the irrigating solution, improves the removal of smear layer. Both of them succeeded in obtaining more clean root canal surface than the traditional syringe irrigation method alone. It is difficult to obtain clean root canal surface specially at the apical third without using an activation method.

\section{Funding:}

Self-funding.

\section{References:-}

1. Torabinejad M, Handysides R, Khademi AA, Bakland LK. Clinical implications of the smear layer in endodontics: a review. Oral Surgery, Oral Medicine, Oral Pathology, Oral Radiology, and Endodontology. 2002;94:658-66.

2. Rajakumaran A, Ramesh H, Ashok R, Balaji L, Ganesh A. Smear layer removal and microhardness alteration potential of a naturally occurring antioxidant - an in vitro study. Cureus. 2019 Jul 25;11(7):e5241.

3. Caron G, Nham K, Bronnec F, Machtou P. Effectiveness of different final irrigant activation protocols on smear layer removal in curved canals. J Endod 2010;36:1361-6

4. ShaimaaRabea, Wael Hussein Kamel, Mohsen M. Nour El Din and Nehal Farouk Sharaf. Comparison of apically extruded debris produced by waveone gold and protaper next after using mechanical or manual glide path techniques Int. J. Adv. Res. 2019 December 7(12):1062-1071

5. SwatyJhamb VN, Singh V. An in vitro study to determine the sealing ability of sealers with and without smear layer removal. Journal of conservative dentistry: JCD. 2009;12:150.

6. Patil PH, Gulve MN, Kolhe SJ, Samuel RM, Aher GB. Efficacy of new irrigating solution on smear layer removal in apical third of root canal: A scanning electron microscope study.JConserv Dent. 2018 MarApr;21(2):190-193. 
7. SankeerthanaKolli, SaravanakarthikeyanBalasubramanian, KittappaKarthikeyan, MahalaxmiSekar. Efficacy of XP- endo Finisher files in endodontics. April 2018 Australian Endodontic Journal 44(1):71-72

8. HakanGöktürk, İsmail Özkoçak, FevziBüyükgebiz. Effect of temperature on the ability of XP-Endo Finisher to remove calcium hydroxide from root canal irregularities: ex vivo 2018 ActaOdontolTurc 2018;35(2):38-43

9. Vaz-Garcia ES, Vieira VTL, Petitet NPDSF, Moreira EJL, Lopes HP, Elias CN, Silva EJNL, Antunes HDS. MechanicalProperties of AnatomicFinishingFiles: XP-EndoFinisher and XP-Clean. Braz Dent J. 2018 AprJun;29(2):208-213.

10. Zeng C, Willison J, Meghil MM, Bergeron BE, Cutler CW, Tay FR, Niu L, Ma J. Antibacterial efficacy of an endodontic sonic-powered irrigation system: An in vitro study.J Dent. 2018 Aug;75:105-112.

11. Urban K, Donnermeyer D, Edgar Schäfer, Bürklein S. Canal cleanliness using different irrigation activation systems:aSEM evaluation. Clin Oral Invest. 2017;21: 2681-2687.

12. Schirrmeister JF1, Liebenow AL, Braun G, Wittmer A, Hellwig E, Al-Ahmad A. Detection and eradication of microorganisms in root-filledteeth associated with periradicular lesions: an in vivo study. J Endod. 2007 May;33(5):536-40. Epub 2007 Mar 12. DOI:10.1016/j.joen.2007.01.012

13. Sirtes G, Waltimo T, Schaetzle M, Zehnder M. The effects of temperature on sodium hypochlorite short-term stability, pulp dissolution capacity, and antimicrobial efficacy.JEndod. 2005 Sep;31(9):669-71. DOI:10.1097/01.don.0000153846.62144.d2

14. Ballal V, Rao S, Al-Haj Husain N, Özcan M. Evaluation of Smear Layer Removal Using Different Irrigation Methods In Root Canals.Eur J ProsthodontRestor Dent. 2019 Aug 29;27(3):97-102. doi: 10.1922/EJPRD_01817Husain06.

15. Nogo-Živanović D, Kanjevac T, Bjelović L, Ristić V, Tanasković I. The effect of final irrigation with MTAD, QMix, and EDTA on smear layer removal and mineral content of root canal dentin.Microsc Res Tech. 2019 Jun;82(6):923-930. doi: 10.1002/jemt.23239. Epub 2019 Feb 20.

16. Mohammadi Z, Shalavi S, Yaripour S, Kinoshita JI, Manabe A, Kobayashi M, Giardino L, Palazzi F, Sharifi F, Jafarzadeh H. Smear Layer Removing Ability of Root Canal Irrigation Solutions: A Review:J Contemp Dent Pract. 2019 Mar 1;20(3):395-402. Review.

17. Dioguardi M, Gioia GD, Illuzzi G, Laneve E, Cocco A, Troiano G. Endodontic irrigants: Different methods to improve efficacy and related problems.Eur J Dent. 2018 Jul-Sep;12(3):459-466. doi: 10.4103/ejd.ejd_56_18. Review.

18. Uzunoglu-Özyürek E, Karaaslan H, Türker SA, Özçelik B. Influence of size and insertion depth of irrigation needle on debris extrusion and sealer penetration. Restor Dent Endod. 2017 Dec 22;43(1):e2. doi: 10.5395/rde.2018.43.e2.

19. Butcher S, Mansour A, Ibrahim M. Influence of Apical Preparation Size on Effective Conventional Irrigation in the Apical Third: A Scanning Electron Microscopic Study.EurEndod J. 2019 Feb 6;4(1):9-14. doi:10.14744/eej.2018.06078.

20. Boutsioukis C, Gogos C, Verhaagen B, Versluis M, Kastrinakis E, Van der Sluis LW. The effect of rootcanaltaper on the irrigantflow: evaluation using an unsteadyComputational Fluid Dynamics model. IntEndod J. 2010 Oct;43(10):909-16. doi: 10.1111/j.1365-2591.2010.01767.x.

21. Agarwal A, Deore RB, Rudagi K, Nanda Z, Baig MO, Fareez MA. Evaluation of Apical Vapor Lock Formation and comparative Evaluation of its Elimination using Three different Techniques: An in vitro Study.JContemp Dent Pract. 2017 Sep 1;18(9):790-794. DOI:10.5005/jp-journals-10024-2128

22. Elnaghy AM, Mandorah A, Elsaka SE. Effectiveness of XP-endo Finisher, EndoActivator, and File agitation on debris and smear layer removal in curved root canals: a comparative study.Odontology. 2017 Apr;105(2):178183. doi: 10.1007/s10266-016-0251-8. Epub 2016 May 20.

23. Bao P, Shen Y, Lin J, Haapasalo M. In Vitro Efficacy of XP-endo Finisher with 2 Different Protocols on Biofilm Removal from Apical Root Canals.J Endod. 2017 Feb;43(2):321-325. doi: 10.1016/j.joen.2016.09.021. Epub 2016 Dec 7.

24. Azimian S, Bakhtiar H, Azimi S, Esnaashari E. In vitro effect of XP-Endo finisher on the amount of residual debris and smear layer on the root canal walls.Dent Res J (Isfahan). 2019 May-Jun;16(3):179-184.

25. Haupt F, Meinel M, Gunawardana A, Hülsmann M. Effectiveness of different activated irrigation techniques on debris and smear layer removal from curved root canals: a SEM evaluation.AustEndod J. 2019 Mar 25.doi: 10.1111/aej.12342.

26. Lee OYS, Khan K, Li KY, Shetty H, Abiad RS, Cheung GSP, Neelakantan P. Influence of apical preparation size and irrigation technique on root canal debridement: a histological analysis of round and oval root canals.IntEndod J. 2019 Sep;52(9):1366-1376. doi: 10.1111/iej.13127. 